\title{
EFEKTIVITAS KOMUNITAS SENI SEBAGAI STRATEGI PROMOSI DI KEDAI KOPI GRESIKNESIA
}

\author{
Rosi Sastrawati \\ Departemen Manajemen, Fakultas Ekonomi dan Bisnis, \\ Universitas Muhammadiyah Gresik, Gresik, Jawa Timur, Indonesia \\ sastrarosi@gmail.com
}

\begin{abstract}
Background - Increasing an effort or business affects intense competition. One of them is in the coffee shop business in Gresik City. In need of effective promotion strategy to face the competition of the coffee shop. In this research the object to be meticulously is the Gresiknesia coffee shop that makes the art community as a promotional strategy. Using an EPIC model (Emphaty, Persuasion, Impact, Communication), researchers will measure the effectiveness of the art community as a promotional strategy at Gresiknesia coffee shop.

Objective - The purpose of this study is to analyze and determine the extent to which the effectiveness of the arts community as a promotional strategy in Gresiknesia coffee shop.

Design : The study uses a qualitative approach with qualitative descriptive methods. To measure effectiveness, researchers take data and information from four key informant and two non-key informant through observation and interviews directly with the support of documentation data.

Findings - The result of the study was that the art community was instrumental in the promotion at the Gresiknesia coffee shop, because the reason visitors came to Gresiknesia coffee shop was to enjoy the event there in addition to enjoying coffee. In addition to the Gresik people, people outside the city also know the Gresiknesia coffee shop because of the art community. So the strategy used in Gresiknesia coffee shop is already effective if measured using EPIC models.

Research implications - This research contributes to marketing management by utilizing art as an added value.

Research limitations - The limitation in this study is to measure the effectiveness of marketing strategies only in terms of promotion using the EPIC model.
\end{abstract}

Keywords: Effectiveness, EPIC Model, promotion, strategy, community, art

\begin{abstract}
Abstrak
Latar Belakang - Meningkatnya sebuah usaha atau bisnis berdampak kepada persaingan yang ketat. Salah satunya pada usaha coffee shop di kota Gresik. Di butuhkan strategi promosi yang efektif untuk menghadapi persaingan usaha coffee shop. Pada penelitian ini objek yang akan di teliti adalah kedai kopi Gresiknesia yang menjadikan komunitas seni sebagai strategi promosi. Penggunaan model EPIC (Emphaty, Persuasi, Impact, Communication), peneliti akan mengukur sejauh mana efektivitas komunitas seni sebagai strategi promosi di kedai kopi Gresiknesia.

Tujuan - Tujuan dari penelitian ini adalah untuk menganalisa dan mengetahui sejauh mana efektifitas komunitas seni sebagai strategi promosi di keda kopi Gresiknesia.

Desain / metodologi / pendekatan - Penelitian ini menggunakan pendekatan kualitatif dengan metode deskriptif kualitatif. Untuk mengukur efektivitas, peneliti mengambil data dan informasi dari empat informan kunci dan dua informan non kunci melalui observasi dan wawancara secara langsung dengan di dukung data dokumentasi.
\end{abstract}


Temuan - Hasil dari penelitian ini adalah komunitas seni sangat berperan dalam segi promosi di kedai kopi Gresiknesia, karena alasan pengunjung datang ke kedai kopi Gresiknesia adalah untuk menikmati acara disana selain untuk menikmati kopi. Selain masyarakat Gresik, masyarakat luar kota juga mengenal kedai kopi Gresiknesia karena komunitas seni. Jadi strategi yang digunakan kedai kopi Gresiknesia sudah efektif jika di ukur menggunakan EPIC model.

Implikasi penelitian - Penelitian ini memberikan sumbangsi dalam manajemen pemasaran dengan memanfaatkan kesenian sebagai nilai tambah yang diberikan.

Batasan penelitian - Batasan pada penelitian ini adalah mengukur efektivitas strategi pemasaran hanya pada segi promosi dengan menggunakan EPIC Model.

Kata kunci : Efektivitas, EPIC Model, Promosi, Strategi, Komunitas, Seni

\section{PENDAHULUAN}

Meningkatnya minat masyarakat pada coffee shop membuat bisnis coffee shop juga semakin banyak di berbagai kota, baik kota besar maupun kota kecil. Dari yang ukuran kecil sampai yang besar salah satunya di kota Gresik. Kota yang saat ini memiliki julukan "Kota Seribu Warung Kopi" karena merebaknya kedai kopi di kota Gresik. Tentu saja hal ini juga berdampak terhadap persaingan bisnis coffee shop semakin ketat. coffee shop yang dulunya menjual rasa kini tidak lagi demikian. Coffee shop juga harus menarik perhatian pelanggan dengan keunikannya. Setiap coffe shop memiliki keunikan dan keunggulan masing-masing (Adji \& Semuel, 2014). Di butuhkan strategi untuk menghadapi persaingan di era saat ini, salah satunya adalah strategi promosi.

Menurut Armstrong and Kotler (2014), promosi adalah aktivitas yang mengkomunikasikan keunggulan produk atau jasa dan membujuk pelanggan untuk membeli produk atau jasa itu. Di kutip dari Jurnal Enterpreneur, 2018 konsep coffee shop yang menarik akan menjadi salah satu strategi pemasaran. Fenomena saat ini, banyak sekali coffee shop khususnya di kota Gresik yang menjadikan konsep desain interior dan eksterior sebagai salah satu strategi pemasaran untuk menarik calon pelanggan dimana tujuannya adalah untuk mendapatkan label instagramable. Artinya tempat menarik bagi generasi millennial sebagai objek fotografi sehingga akan terlihat cantik ketika dipublikasi di sosial media. Hal ini akan menjadi salah satu bagian dari strategi promosi untuk memperkenalkan coffee shop mereka secara luas.

Faktanya ada kedai kopi di kota Gresik yang memiliki strategi lain tentunya tidak dengan mengunggulkan konsep desain sebagai strategi pemasarannya yang mana juga sebagai objek dari penelitian ini, yaitu kedai kopi Gresiknesia yang berlokasi di Perum Pongangan Indah GKB (Gresik Kota Baru). Dimana memiliki komunitas seni sebagai 
strategi promosi atau memperkenalkan ke banyak orang, jadi komunitas itu tidak hanya sebagai pengunjung tetap saja tetapi sudah menjadi bagian dari kedai kopi Gresiknesia artinya sangat berperan dalam kemajuan kedai kopi Gresiknesia. Kedai kopi Gresiknesia merupakan wadah kreatif komunitas seni di Gresik yang berupa kedai kopi dibawah naungan Yayasan Gang Sebelah, yang mana sebelum lahir kedai kopi Gresiknesia, ada 2 komunitas seni yakni Gresik Movie dan Sanggar Intra. Kedua komunitas itu membutuhkan tempat atau wadah untuk mereka berdiskusi satu sama lain dan tujuannya juga untuk memperbanyak jaringan yang akhirnya mereka membuat kedai kopi Gresiknesia dengan menerapkan karya-karya mereka sebagai bentuk pembeda dari kedai kopi yang lain.

Kedai kopi bukan hanya untuk tempat penghilang kantuk, tempat nongkrong ataupun tempat untuk menghabiskan waktu bersama kolega namun juga sebagai tempat diskusi kecil. Pada akhirnya semakin banyak yang tertarik untuk nongkrong dan berdiskusi di kedai kopi Gresiknesia hingga terbentuk komunitas-komunitas seni yang baru sebagai ruang publik modern untuk menuangkan aspirasi seni yang bisa menopang strategi pemasaran khususnya pada segi promosi di kedai kopi Gresiknesia. Diantaranya, grup musik puisi Onomastika, kelompok seni rupa Partikel Bebas, Ruang Baca alternatif (Rubamerah), startup Gresiknesia Store dalam bidang kreatif, dan Sanggar Intra. Terdapat beberapa momen rutin atau kegiatan yang diselenggarakan di kedai kopi Gresiknesia yang mana juga mengundang beberapa narasumber untuk lebih memperkaya ilmu tentang seni maupun kopi. Hal ini membuat semakin banyak pengunjung di kedai kopi Gresiknesia, selain dapat menikmati kopi dan jajanan lainnya, pengunjung juga mendapatkan experience (pengalaman) tersendiri yang mana itu menjadi prinsip dari kedai kopi Gresiknesia sebagai Branding mereka.

\section{Tabel 1}

Kegiatan yang diselenggarakan di kedai kopi Gresiknesia tahun 2019

\begin{tabular}{|c|c|c|}
\hline BULAN & KEGIATAN & TEMPAT \\
\hline \multirow{3}{*}{ JULI } & $\begin{array}{l}\text { 1. Acara rilis album pertama dari komunitas } \\
\text { Onomastika "Musim" }\end{array}$ & \multirow{3}{*}{$\begin{array}{l}\text { KEDAI KOPI } \\
\text { GRESIKNESIA }\end{array}$} \\
\hline & $\begin{array}{l}\text { 2. Pembukaan casting film untuk project film Gresik } \\
\text { Movie "Salah melihat jalan surga" }\end{array}$ & \\
\hline & 3. Festival menemukan luka & \\
\hline AGUSTUS & Festival kedai kopi Gresiknesia & $\begin{array}{l}\text { KEDAI KOPI } \\
\text { GRESIKNESIA }\end{array}$ \\
\hline SEPTEMBER & $\begin{array}{l}\text { baca buku (kegiatan rutin di rubah merah) kedai kopi } \\
\text { Gresiknesia }\end{array}$ & $\begin{array}{l}\text { KEDAI KOPI } \\
\text { GRESIKNESIA }\end{array}$ \\
\hline OKTOBER & 1. sinoman (Sinau Noto Mandolo) & \\
\hline
\end{tabular}




\begin{tabular}{|c|c|c|}
\hline & 2. Diskusi dengan tema "Komunitas Sebagai Aset Kota" & $\begin{array}{l}\text { KEDAI KOPI } \\
\text { GRESIKNESIA }\end{array}$ \\
\hline \multirow{4}{*}{ NOVEMBER } & 1. pemutaran film Festival Aksara 2019 & \multirow{4}{*}{$\begin{array}{l}\text { KEDAI KOPI } \\
\text { GRESIKNESIA }\end{array}$} \\
\hline & 2. sinoman (Sinau Noto Mandolo) & \\
\hline & 2. diskusi dengan tema Ekologi Kota Bandar & \\
\hline & $\begin{array}{l}\text { 3. pemutaran film Hujan dan Aroma Ikan dari Gresik } \\
\text { Movie }\end{array}$ & \\
\hline
\end{tabular}

Sumber : Kedai Kopi Gresiknesia 2019

Beberapa kegiatan yang diselenggarakan di kedai kopi Gresiknesia ini merupakan projek-projek dari beberapa komunitas seni yang ada didalamnya. Dimana seluruh komunitas seni sangat berperan untuk mempromosikan kedai kopi Gresiknesia. Karena hal ini akan menarik para pengunjung untuk datang. Berdasarkan latar belakang, tujuan dari penelitian ini adalah untuk menganalisa dan mengetahui sejauh mana efektifitas komunitas seni sebagai strategi promosi di Kedai Kopi Gresiknesia.

\section{TINJAUAN PUSTAKA}

\section{Penelitian Terdahulu}

Penelitian terdahulu yang relevan adalah penelitian yang dilakukan oleh Adhanisa, Chikameirani, and Fatchiya (2017) dengan Fokus penelitian yaitu mengukur sejauh mana efektivitas website dan instagram sebagai strategi promosi kawasan wisata berbasis masyarakat dengan menggunakan aspek AIDA (attention, interest, desire, action) dan juga menganalisa faktor yang mempengaruhi website dan instagram sebagai strategi promosi kawasan wisata berbasis masyarakat. Berdasarkan penelitian ini didapatkan hasil yaitu (1)Website dan Instagram yang digunakan oleh Desa Wisata Gabugan sebagai media promosinya hanya efektif untuk menarik perhatian (attention) dan juga menarik keingintahuan (interest) responden terhadap kawasan wisata. Namun untuk menarik keinginan (desire) dan tindakan (action) responden untuk membeli jasa yang ditawarkan masih kurang. (2) Efektivitas website sebagai media promosi di Desa Wisata Gabugan dipengaruhi oleh kelengkapan informasi, sedangkan pada instagram dipengaruhi oleh kelengkapan informasi dan tata bahasa.

Penelitian selanjutnya dilakukan oleh Amanah (2018). Hasil penelitian dapat disimpulkan bahwa (1) Strategi promosi yang telah diterapkan oleh IAIN Kediri yakni melalui penyebaran brosur, pamflet, pemasangan spanduk, pemasangan baliho, pemasangan iklan di media cetak, pemasangan di media elektronik dan media on- line. Penggunaan media dalam strategi promosi pada IAIN Kediri selama tiga tahun 
menunjukkan ketidakefektifan jenis media dalam strategi promosi yang dipilih namun ada peningkatan melalui media on-line (2) Kurang efektifnya strategi promosi yang dipergunakan oleh IAIN Kediri dikarenakan selama kurun waktu tiga tahun disebabkan salah satunya intensitas penggunaan alat promosi dalam strategi promosi relatif tetap, serta belum adanya petugas bagian humas secara khusus dan sah oleh pimpinan IAIN Kediri sehingga strategi promosi pemasaran walaupun belum sepenuhnya optimal.

\section{Landasan Teori}

\section{Pengertian Promosi}

Menurut Armstrong and Kotler (2014) promosi adalah aktivitas yang mengkomunikasikan keunggulan produk atau jasa dan membujuk pelanggan untuk membeli produk atau jasa itu.

\section{Pengertian Strategi}

Menurut Fred (2011) Strategi adalah sarana bersama dengan tujuan jangka panjang yang hendak dicapai. Strategi bisnis mencakup ekspansi georafis, diversifikasi, akusisi, pengembangan produk, penetrasi pasar, pengetatan, divestasi, likuidasi, dan usaha patungan atau joint venture.

\section{Cara Mengukur Efektivitas Strategi Promosi dengan EPIC Model}

EPIC model merupakan suatu model yang cocok dipergunakan untuk mengukur efektivitas promosi. Durianto (2003) mengungkapkan bahwa EPIC model yang kembangkan oleh AC Nielsena (sebuah perusahaan peneliti pemasaran yang memiliki reputasi kelas dunia), memiliki empat dimensi kritis, yaitu: empati (Empathy), persuasi (Persuation), dampak (Impact) dan komunikasi (Comunication). Model EPIC memiliki keunggulan dalam mengukur efektivitas promosi dibandingkan dengan model lainnya (Himawan, 2019). Dimensi Empati (Empathy), dimensi ini memberikan informasi yang berharga tentang daya tarik suatu merek. Dimensi Persuasi (Persuation), dimensi persuasi ini menginformasikan apa yang dapat diberikan suatu iklan untuk peningkatan atau penguatan karakter suatu merek. Dimensi Dampak (Impact), dimensi ini menunjukkan apakah suatu merek dapat terlihat menonjol dibandingkan merek lain pada kategori yang serupa dan apakah suatu merek mampu melibatkan konsumen dalam pesan yang disampaikan. Dimensi Komunikasi (Comunication), dimensi ini 
memberikan informasi tentang kemampuan konsumen dalam mengingat pesan utama yang disampaikan, pemahaman konsumen serta kekuatan kesan yang ditinggalkan pesan tersebut.

\section{METODOLOGI PENELITIAN}

Penelitian ini menggunakan pendekatan kualitatif dengan metode deskriptif kualitatif. Untuk mengukur efektivitas, peneliti mengambil data dan informasi dari empat informan kunci dan dua informan non kunci melalui observasi dan wawancara secara langsung dengan di dukung data dokumentasi.

\section{HASIL DAN PEMBAHASAN}

Pada penelitian ini peneliti memaksimalkan pengumpulan datanya melalui wawancara secara langsung, dimana pengunjung sebagai informan kunci karena pada penelitian ini pengukuran efektivitas strategi promosi menggunakan EPIC Model yang mana sangat di butuhkan beberapa informasi dari pengunjung kedai kopi Gresiknesia terlebih mengetahui tentang sejauh mana mereka tertarik dan apa alasannya. Selanjutnya adalah wawancara dengan pihak dari kedai kopi Gresiknesia yaitu pengelola dan salah satu perwakilan (penanggung jawab) dari beberapa komunitas seni yang ada di kedai kopi Gresiknesia. Dimana membahas tentang sejauh mana pencapaian kedai kopi Gresiknesia ketika menerapkan strategi promosi itu dan sejauh mana kedai kopi Gresiknesia di kenal orang. Setelah melakukan penelitian di kedai kopi Gresiknesia, di dapatkan hasil bahwa strategi promosi yang di terapkan di kedai kopi Gresiknesia bisa dikatakan efektif jika di ukur menggunakan EPIC Model (Emphaty, Persuasi, Impact, Communication). Dengan penjelasan :

\section{Dimensi Empati (emphaty)}

Strategi promosi memang sangat mempengaruhi seseorang memutuskan untuk berkunjung ke kedai kopi Gresiknesia. Baik itu kadang kadang ataupun pengunjung yang terus menerus ingin datang seperti yang sudah dipaparkan di atas. Tentu saja dibalik itu semua pasti ada alasan tersendiri kenapa bisa tertarik untuk mengunjungi suatu tempat atau yang peneliti bahas disini adalah kedai kopi Gresiknesia. Dari pengukuran dimensi Empati, Peneliti dapat menyimpulkan bahwa Strategi promosi 
yang di terapkan di kedai kopi Gresiknesia efektif jika diukur menggunakan dimensi Empati (Emphaty).

Hasil dari wawancara dan analisa menyimpulkan bahwa dengan menyelenggarakan beberapa kegiatan setiap bulannya di kedai kopi Gresiknesia membuat pengunjung menjadi loyal atau sering mengunjungi kedai kopi Gresiknesia seperti yang di ungkapkan oleh beberapa pengunjung saat dilakukan wawancara. Hal ini tentu di dukung dengan data dari kedai kopi Gresiknesia tentang perbedaan jumlah pengunjung ketika ada kegiatan dan ketika tidak ada kegiatan di kedai kopi Gresiknesia. Yang mana menjadi nilai penting untuk mengukur efektif tidaknya strategi promosi di kedai kopi Gresiknesia.

Peneliti juga berpendapat bahwa awal mula pengunjung bisa mengenal dan bisa mengetahui adanya kedai kopi Gresiknesia adalah dari postingan unik di sosial media yang di lakukan oleh pihak kedai kopi Gresiknesia yaitu dengan tidak memposting menu makanan atau minuman tetapi memposting pamflet atau brosur kegiatan yang akan di selenggarakan di kedai kopi Gresiknesia, mengingat tempat atau lokasi kedai kopi Gresiknesia ada di tengah perumahan bahkan menurut peneliti kurang strategis untuk bisa dijangkau dan di ketahui pengunjung oleh karena itu sangat efektif jika memanfaatkan postingan unik di sosial media untuk bisa memperkenalkan kedai kopi Gresiknesia kepada calon pelanggan. Hal ini juga sesuai dengan hasil wawancara dengan beberapa pengunjung di kedai kopi Gresiknesia.

\section{Dimensi Persuasi}

Dari beberapa pandangan dan pendapat, peneliti dapat menarik kesimpulan bahwa strategi promosi yang di terapkan di kedai kopi Gresiknesia efektif jika diukur menggunakan dimensi perusasi karena pada dimensi ini peneliti mendapatkan informasi tentang penilaian strategi promosi dari beberapa pengunjung yang mana pendapat itu juga sesuai dengan tujuan dari pihak kedai kopi Gresiknesia yaitu menerapkan strategi promosi dengan adanya komunitas seni didalamnya agar terlihat unik dan berbeda dengan kedai kopi lainnya. Serta sesuai dengan peran komunitas seni di kedai kopi Gresiknesia yang sangat besar dari segi pemasarannya yang di ungkapkan oleh pihak kedai kopi Gresiknesia. Jadi bisa dikatakan strategi promosinya berhasil menarik perhatian konsumen dengan strategi promosi yang diterapkan saat ini. 


\section{Dimensi Dampak (Impact)}

Berdasarkan argumen dan pendapat yang sudah di paparkan, peneliti dapat menarik kesimpulan bahwa strategi promosi yang di terapkan di kedai kopi Gresiknesia efektif jika di ukur menggunakan dimensi dampak atau impact karena menurut pihak kedai kopi Gresiknesia, bukan hanya pengunjung dari kota Gresik saja yang mengenal kedai kopi Gresiknesia karena komunitas seninya tetapi juga dari luar kota Gresik. Pendapat ini sesuai dengan hasil wawancara dengan pengunjung, yaitu mereka bisa berdiskusi secara langsung dengan beberapa anggota komunitas seni di kedai kopi Gresiknesia karena pengunjung bisa kenal baik dengan anggota komunitas seni disana sehingga bisa membuat pengunjung merasa nyaman untuk berkunjung dan berpartisipasi menonton event di kedai kopi Gresiknesia.

\section{Dimensi Komunikasi (Communication)}

Dari beberapa argumen di atas, peneliti dapat menarik kesimpulan bahwa strategi promosi yang di terapkan di kedai kopi Gresiknesia efektif jika di ukur menggunakan dimensi komunikasi (communication) karena hasil dari wawancara kepada pengunjung terkait dengan kesan dan pengalaman menarik setelah mengunjungi kedai kopi Gresiknesia sesuai atau relevan dengan tujuan pihak kedai kopi Gresiknesa menerapkan strategi promosi yaitu untuk menarik pengunjung yang datang ke kedai kopi Gresiknesia sehingga bisa memberikan kesan dan pengalaman menarik kepada pengunjung.

Budaya inovasi adalah hasil dari keseluruhan interaksi multifaset antara dimensi kunci dan nilai-nilai yang tertanam dalam budaya organisasi. Nilai-nilai ini termasuk fleksibilitas, visi ke depan, pemberdayaan, apresiasi ide, toleransi resiko, komunikasi, dorongan, dan pengambilan keputusan bersama. Maka, proses inovasi tidak akan menjadi aktivitas yang dapat dibagi, sebaliknya, harus terjadi dalam budaya yang terdiri dari seperangkat nilai yang dianut secara koheren untuk memfasilitasi praktik inovasi yang sedang berlangsung (Ismail, Khairuzzaman, \& Majid, 2007).

Hasil penelitian kualitatif mengenai penerapan budaya inovasi, faktor penghambat dan upaya untuk meminimalisirnya menunjukkan bahwa strategi yang digunakan perusahaan untuk menerapkan budaya tersebut adalah dengan melakukan sosialisasi ke seluruh jajaran karyawan mengenai pentingnya melakukan inovasi untuk keberlangsungan hidup perusahaan. Sosialisasi yang digunakan perusahaan dari hasil 
penelitian ini adalah dengan diadakannya konvensi inovasi yang rutin yang diadakan setiap tahun, yang mana didalam acara ini ide-ide inovasi karyawan di tiap-tiap unit kerjanya akan di lombakan. Tujuan ini diterapkan perusahaan agar para karyawannya selalu berperilaku inovatif.

Budaya inovasi dalam organisasi perlu ditanamkan, karena dipandang sebagai kebutuhan vital, dan organisasi perlu menyediakan dukungan yang diperlukan untuk melancarkan proses tersebut. Seperti yang diucapkan oleh informan bapak Gunawan bahwa "top manajemen malah mendukung adanya budaya inovasi ini. Apalagi jajaran direksi, mereka malah seneng liat karyawan-karyawannya aktif demi kemajuan perusahaan". Inovasi mampu menjadi motivasi kerja karyawan karena setiap karyawan mampu menciptakan metode kerja baru yang lebih mudah dan membuat mereka nyaman dalam bekerja dan mampu menjadi motivasi agar bekerja lebih giat. Harapan dari penerapan budaya ini, perusahaan dapat mengefisiensi biaya operasional perusahaan yang akan berpengaruh pada peningkatan margin perusahaan.

Dalam penerapan budaya tersebut, terdapat pula kendala-kendala yang menjadi penghambat kesuksesan penerapannya. Berdasarkan hasil dari penelitian ini, ditemukan beberapa faktor yang menjadi penghambat suksesnya penerapan budaya tersebut. Salah satunya yaitu karakter karyawan yang apabila tidak diberi perintah tidak akan jalan, karyawan yang tidak ingin maju dengan pemikiran kuno yang menganggap inovasi sebagai beban kerja tambahan, dan karyawan yang merasa perusahaan di tempat dia bekerja masih eksis jadi tidak perlu ada perubahan atau inovasi.

\section{KESIMPULAN}

\section{Dimensi Empati (emphaty)}

Dari pengukuran dimensi empati, eneliti dapat menyimpulkan bahwa strategi promosi yang di terapkan di kedai kopi Gresiknesia efektif jika diukur menggunakan dimensi empati (Emphaty). Dimana dengan menyelenggarakan beberapa kegiatan setiap bulannya di kedai kopi Gresiknesia membuat pengunjung menjadi loyal atau sering mengunjungi kedai kopi Gresiknesia.

\section{Dimensi Persuasi}

Dari pengukuran dimensi persuasi, peneliti dapat menyimpulkan bahwa strategi promosi yang di terapkan di kedai kopi Gresiknesia efektif jika diukur menggunakan 
dimensi persuasi. karena pada dimensi ini peneliti mendapatkan informasi tentang penilaian strategi promosi dari beberapa pengunjung yang mengatakan strategi promosi di kedai kopi Gresiknesia sangat unik dan berbeda dengan kedai kopi lainnya. Serta sesuai dengan peran komunitas seni di kedai kopi Gresiknesia yang sangat besar dari segi pemasarannya. Jadi bisa dikatakan strategi promosinya berhasil menarik perhatian konsumen dengan strategi promosi yang diterapkan saat ini.

\section{Dimensi Dampak (Impact)}

Dari pengukuran dimensi dampak, peneliti dapat menyimpulkan bahwa strategi promosi yang di terapkan di kedai kopi Gresiknesia efektif jika diukur menggunakan dimensi dampak (Impact) karena menurut pihak kedai kopi Gresiknesia, bukan hanya pengunjung dari kota Gresik saja yang mengenal kedai kopi Gresiknesia karena komunitas seninya tetapi juga dari luar kota Gresik. Selain itu pengunjung juga bisa berdiskusi secara langsung dengan beberapa anggota komunitas seni di kedai kopi Gresiknesia sehingga bisa membuat pengunjung merasa nyaman untuk berkunjung dan berpartisipasi menonton event di kedai kopi Gresiknesia.

\section{Dimensi Komunikasi (Communication)}

Dari pengukuran dimensi komunikasi (Communication), peneliti dapat menyimpulkan bahwa strategi promosi yang di terapkan di kedai kopi Gresiknesia efektif jika diukur menggunakan dimensi komunikasi karena hasil dari wawancara kepada pengunjung terkait dengan kesan dan pengalaman menarik setelah mengunjungi kedai kopi Gresiknesia sesuai atau relevan dengan tujuan pihak kedai kopi Gresiknesa menerapkan strategi promosi yaitu untuk menarik pengunjung yang datang ke kedai kopi Gresiknesia sehingga bisa memberikan kesan dan pengalaman menarik kepada pengunjung.

\section{REKOMENDASI}

Bagi peneliti selanjutnya masih banyak objek di kedai lain yang perlu untuk di teliti. Mungkin jika peneliti selanjutnya meneliti kedai kopi Gresiknesia, bisa dengan menggunakan teori atau model lain untuk mengukur efektivitas strateginya. Dan tidak hanya menganalisa tentang promosi saja tetapi bisa menganalisa tentang marketing mix lainnya yang mash berhubungan dengan strategi pemasaran. 


\section{DAFTAR PUSTAKA}

Adhanisa, Chikameirani, \& Fatchiya, A. (2017). Efektivitas website dan instagram sebagai sarana promosi kawasan wisata berbasis masyarakat. Jurnal Sains Komunikasi Dan Pengembangan Masyarakat, 1(4), 451-466.

Adji, J., \& Semuel, H. (2014). Pengaruh Satisfaction Dan Trust Terhadap Minat Beli Konsumen (Purchase Intention) Di Starbucks The Square Surabaya. Jurnal Manajemen Pemasaran Petra, 2(1), 1-10.

Amanah, S. (2018). Efektivitas Strategi Promosi Melalui Promotion MIX sebagai Upaya Penguatan Eksistensi Lembaga STAIN Kediri. Jurnal Mediakita: Jurnal Komunikasi dan Penyiaran Islam, 2(2).

Armstrong, \& Kotler. (2014). Principles of Marketing. England: Penerbit Pearson, Inc.

Durianto, d. (2003). Invasi Pasar dengan Iklan yang Efektif: Strategi, Program, dan Teknik Pengukuran. Jakarta: Gramedia Pustaka Utama.

Fred, D. R. (2011). Manajemen Strategies. Jakarta: Penerbit Salemba Empat.

Himawan, A. F. I. (2019). Digital Marketing: Peningkatan Kapasitas Dan Brand Awareness Usaha Kecil Menengah. Jurnal Analisis Bisnis Ekonomi, 17(2), 85-103.

Ismail, W., Khairuzzaman, W., \& Majid, A. (2007). Framework of the culture of innovation: A Revisit. Jurnal Kemanusiaan, 9, 38-49. 